\title{
GMR
}

\section{Characterization of maize genotypes for genetic diversity on the basis of inter simple sequence repeats}

\author{
R.W. Muhammad², A. Qayyum', M.Q. Ahmad', A. Hamza', M. Yousaf', \\ B. Ahmad ${ }^{3}$, M. Younas ${ }^{1}$, W. Malik', S. Liaqat ${ }^{1}$ and E. Noor ${ }^{1}$ \\ ${ }^{1}$ Department of Plant Breeding and Genetics, \\ Faculty of Agricultural Sciences and Technology, Bahauddin Zakariya University, \\ Multan, Pakistan \\ ${ }^{2}$ PARC Research and Training Station, Pakistan Agriculture Research Council, \\ Multan, Pakistan \\ ${ }^{3}$ Arid Zone Research Institute, PARC, Bahawalpur \\ Corresponding author: R.W. Muhammad \\ E-mail: waliparc@gmailcom \\ Genet. Mol. Res. 16 (1): gmr16019438 \\ Received October 17, 2016 \\ Accepted February 20, 2017 \\ Published March 30, 2017 \\ DOI http://dx.doi.org/10.4238/gmr16019438
}

Copyright (C) 2017 The Authors. This is an open-access article distributed under the terms of the Creative Commons Attribution ShareAlike (CC BY-SA) 4.0 License.

ABSTRACT. Genetic diversity in crops is essential to make
improvements related to superior germplasms. Implementation
of molecular markers to identify suitable genotypes speeds up the
breeding progress by enhancing selection efficiency. This study was
carried out to probe genetic diversity among 21 maize genotypes using
20 inter simple sequence repeat (ISSR) markers. We identified a total
of 190 polymorphic bands with an average of 9.5 alleles per primer.
The highest number of polymorphic bands (17) was found using
ISSR marker UBC-10, whereas the lowest number of polymorphic
bands (4) was found using UBC-809. The coefficient of genetic
similarity ranged from 0.888 to $0.118 \%$. The highest similarity was
found between accessions 12 (015224) and $9(015114)$, whereas the
lowest similarity was found between genotypes 20 (EV-5098) and 14

Genetics and Molecular Research 16 (1): gmr16019438 
(015030). The polymorphism information content ranged from 0.17 to 0.47 . A dendrogram was generated based on Jaccard's distance matrix. The genotypes were found to group into two major clusters that could be further partitioned into two sub-clusters. Genotypes located within the same cluster are genetically more closely related to each other. The present study efficiently identified diverse genotypes that may be used for creating new varieties with distinct characteristics. The identified genotypes could be used as parents for future development of diverse populations.

Key words: Maize genotypes; ISSR markers; Polymorphism; Genetic diversity; Dendrogram

\section{INTRODUCTION}

Maize (Zea mays L.) is an important cereal crop belonging to the genus Zea, family Poaceae, and tribe Maydeae. It is widely grown across the globe and ranked third following wheat and rice in production. To produce new cultivars under changing environmental conditions the importance of genetic diversity cannot be ignored. Exploration of genetic diversity to obtain useful variation has great potential for crop breeding programs. In maize, evaluation of genetic diversity is a pre-requisite for the production of diverse inbred lines and has a pivotal importance for the development of transgressive hybrids. It is also important for germplasm improvement and development of maize synthetics with novel genes for desired traits associated with biotic and abiotic stress tolerance (Hoxha et al., 2004).

Genetic diversity analyses can be performed using different methods including those using morphological traits, pedigree records, and molecular markers (Cox et al., 1986; Marić et al., 1998). Genetic diversity assessments based on morphological markers have been extensively used in various crop plants to generate information for breeding programs (Hoxha et al., 2004; Sajjad et al., 2011).

The evaluation of genetic diversity based on morphological markers is a timeconsuming process. Furthermore, it does not portray the exact nature of the genetic diversity in a species because morphological traits are greatly influenced by environmental factors. Similarly, markers based on biochemical and cytological parameters have also been used to determine genetic diversity in crop plants. Due to their limited coverage, these markers are unable to evaluate the whole genome of crop plants (Islam and Shepherd, 1992). Compared with other marker systems, molecular marker systems are generally considered to be independent of environmental influences and have greater genome coverage. Molecular markers are consistent in the entire plant body. Therefore, these markers are not influenced by pleiotropic, epistatic, or environmental factors (Agarwal et al., 2008). Molecular markers have offered tremendous contributions in the exploration of genetic diversity, population structure analyses, and gene mapping in a number of species (Helentjaris et al., 1986; Ahmad et al., 2014). Furthermore, molecular markers have successfully been used to tag genomic regions linked with trait expression. These functional markers could be used for marker assisted selection (MAS) in variety development programs.

Commonly used molecular markers are simple sequence repeat markers (SSRs), randomly amplified polymorphic DNA markers, single nucleotide polymorphisms, and inter

Genetics and Molecular Research 16 (1): gmr16019438 
simple sequence repeats (ISSRs) (Tautz, 1989; Welsh and McClelland, 1990; Reddy et al., 2002). Data generated using these markers are used for the development of genetic maps in almost all field crops. These markers are the best choice to identify variation among different accessions due to easiness in their use, cost and repeatability of the results (Schlötterer, 2004; Schulman, 2007; Bernardo, 2008). These markers are extremely useful to estimate genetic distance because they are not affected by the environment. Among different marker systems, the ISSR system is the most efficient and reproducible (Reddy et al., 2002). ISSR markers successfully target multiple SSR loci dispersed across the genome. Therefore, ISSRs are useful for identifying diverse genotypes by producing a large number of markers (Dalamu Behera et al., 2012).

The present study was conducted to estimate genetic variation at the molecular level among maize germplasms using ISSR markers. The aim was to identify the most genetically variable genotypes that may be used in future breeding programs to develop promising genetic materials with improved maize crop characteristics.

\section{MATERIAL AND METHODS}

We evaluated 21 maize genotypes with different origins (Table 1). We used ISSR markers in the genomics laboratory of the Department of Plant Breeding and Genetics, Faculty of Agricultural Sciences and Technology, Bahauddin Zakaryia University, Multan. The genotypes used in this study were selected on the basis of their diverse performance under water limited conditions.

Table 1. Plant accessions of maize genotypes including parentage and origin.

\begin{tabular}{l|c|l|l|c|c|l|l}
\hline Serial No. & Accession No. & Parentage & Origin & Sr. No. & Accession No. & Parentage & Origin \\
\hline 01 & 014867 & LUTAN NO.31 & Pakistan & 12 & 015224 & $003834(02)$ & Pakistan \\
\hline 02 & 014910 & $000404(04)$ & Pakistan & 13 & 015167 & $002275(03)$ & Pakistan \\
\hline 03 & 014934 & $000467(04)$ & Pakistan & 14 & 015030 & LINFINHAUNG & China \\
\hline 04 & 014936 & $000472(05)$ & Pakistan & 15 & 015125 & TL 78A-37 & Mexico \\
\hline 05 & 014955 & $000608(04)$ & Pakistan & 16 & 015129 & TL 76B 210 & Mexico \\
\hline 06 & 015060 & $000963(02)$ & Pakistan & 17 & 015262 & P-3282 & Japan \\
\hline 07 & 015250 & $003870(05)$ & Pakistan & 18 & Sahiwal-2002 & Pakistan & \\
\hline 08 & 015084 & $000995(02)$ & Pakistan & 19 & Agaiti-2002 & Pakistan & \\
\hline 09 & 015114 & $001025(01)$ & Pakistan & 20 & EV-5098 & Pakistan & \\
\hline 10 & 015182 & $002398(03)$ & Pakistan & 21 & EV-6098 & Pakistan & \\
\hline 11 & 015135 & $001280(05)$ & Pakistan & & & &
\end{tabular}

\section{DNA extraction}

The DNA extract was obtained from the tissue of the 21 genotypes when the seedlings were 4 days old. DNA was extracted using the CTAB method as explained by Edwards et al. (1991). Leaf tissue $(0.5 \mathrm{~g}$ ) was ground into a fine powder, using liquid nitrogen in pre-chilled pestle and mortar. Pre-heated $\left(1 \mathrm{~mL}, 65^{\circ} \mathrm{C}\right) \mathrm{CTAB}$ buffer was added to the leaf tissue powder. Of this solution, $750 \mu \mathrm{L}$ was placed in Eppendorf tubes and placed in a hot water bath at $65^{\circ} \mathrm{C}$ for $45 \mathrm{~min}$. An equal volume of chloroform isoamyl alcohol was added to the solution and mixed gently followed by centrifugation at $13,000 \mathrm{~g}$ for $10 \mathrm{~min}$.

The supernatant was transferred to new Eppendorf tubes and pre-chilled isopropanol was added. The solution was then mixed gently until DNA threads could be observed. The

Genetics and Molecular Research 16 (1): gmr16019438 
solution was incubated at $-70^{\circ} \mathrm{C}$ for 10 min followed by 10 min centrifugation at $13,000 \mathrm{~g}$. The supernatant was discarded and the DNA pellets were washed with $70 \%$ ethanol. The ethanol was removed from the samples that were then allowed to dry for $2 \mathrm{~h}$. After dissolving the pellet in $150 \mu \mathrm{L}$ water, the DNA samples were stored at $-20^{\circ} \mathrm{C}$ until further use. The DNA concentration was estimated using a Nanophotometer (1286, Implen, UK) as well as using a gel electrophoresis procedure.

\section{Polymerase chain reaction (PCR) amplification}

For the genetic diversity analysis, 21 maize accessions were explored using 20 ISSR markers. These markers had been successfully utilized for molecular characterization by Ashraf et al. (2016). A detailed list of the ISSR markers along with their sequences and annealing temperatures is presented in Table 2 .

\begin{tabular}{|c|c|c|c|c|}
\hline Sr. No & Primer name & Primer sequence 5'-3' & Length (bp) & Annealing temperature $\left({ }^{\circ} \mathrm{C}\right)$ \\
\hline 1 & UBC-801 & ATA TAT ATA TAT ATA TT & 17 & 52 \\
\hline 2 & UBC-802 & ATA TAT ATA TAT ATA TG & 17 & 52 \\
\hline 3 & UBC-803 & ATA TAT ATA TAT ATA TC & 17 & 52 \\
\hline 4 & UBC-804 & TAT ATA TAT ATA TAT AA & 17 & 52 \\
\hline 5 & UBC-805 & TAT ATA TAT ATA TAT AC & 17 & 52 \\
\hline 6 & UBC-806 & TAT ATA TAT ATA TAT AG & 17 & 52 \\
\hline 7 & UBC-807 & AGA GAG AGA GAG AGA GT & 17 & 52 \\
\hline 8 & UBC-808 & AGA GAG AGA GAG AGA GC & 17 & 52 \\
\hline 9 & UBC-809 & AGA GAG AGA GAG AGA GG & 17 & 52 \\
\hline 10 & UBC- 810 & GAG AGA GAG AGA GAG AT & 17 & 52 \\
\hline 11 & UBC-811 & GAG AGA GAG AGA GAG AC & 17 & 52 \\
\hline 12 & UBC-812 & GAG AGA GAG AGA GAG AA & 17 & 52 \\
\hline 13 & UBC-813 & CTC TCT CTC TCT CTC TT & 17 & 52 \\
\hline 14 & UBC-814 & CTC TCT CTC TCT CTC TA & 17 & 52 \\
\hline 15 & UBC-815 & CTC TCT CTC TCT CTC TG & 17 & 52 \\
\hline 16 & UBC-816 & CAC ACA CAC ACA CAC AT & 17 & 52 \\
\hline 17 & UBC-817 & CAC ACA CAC ACA CAC AA & 17 & 52 \\
\hline 18 & UBC-818 & CAC ACA CAC ACA CAC AG & 17 & 52 \\
\hline 19 & UBC-819 & GTG TGT GTG TGT GTG TA & 17 & 52 \\
\hline 20 & UBC-820 & GTG TGT GTG TGT GTG TC & 17 & 52 \\
\hline
\end{tabular}

The PCR reaction mixture added up to a total volume of $20 \mu \mathrm{L}$ and contained 2.0 $\mu \mathrm{L}$ Taq buffer, $2.0 \mu \mathrm{L}$ ISSR primer, $2.5 \mu \mathrm{L} \mathrm{MgCl}_{2}, 11.3 \mu \mathrm{L} \mathrm{d}_{3} \mathrm{H}_{2} \mathrm{O}, 1.0 \mu \mathrm{L}$ dNTPs, $0.2 \mu \mathrm{L}$ TaqDNA Polymerase, and $1.0 \mu \mathrm{L}$ template DNA. In each PCR tube containing $1 \mu \mathrm{L}$ template DNA, $19 \mu \mathrm{L}$ master mix was dispensed. The PCR tubes were then placed on a thermocycler machine (Bio Rad, Power Pac, Universal power supply, Singapore) after a brief spinning. The amplification conditions consisted of an initial denaturation step of 4 min at $94^{\circ} \mathrm{C} ; 40$ cycles of $1 \mathrm{~min}$ at $94^{\circ} \mathrm{C}, 1 \mathrm{~min}$ at $52^{\circ} \mathrm{C}$, and $2 \mathrm{~min}$ at $72^{\circ} \mathrm{C}$; followed by a final elongation step of 10 min at $72^{\circ} \mathrm{C}$. The PCR products were separated on $2 \%$ agarose gel.

\section{Statistical analysis}

For the ISSR marker analysis, the gels were scored for band presence/absence, generating a binary matrix. A genetic similarity matrix was calculated on the basis of Jaccard's similarity coefficients using the unweighted pair-group of arithmetic means (UPGMA)

Genetics and Molecular Research 16 (1): gmr16019438 
procedure. A dendrogram was also drawn using similarity coefficients as suggested by Randi et al. (1989). All analyses were carried out using NTSYS v. 3 software system. The polymorphism information content (PIC) value of each primer was determined using the formula suggested by Ghislain et al. (1999):

$$
P I C=1-[(p) 2+(q) 2]
$$

in which $p$ denotes the frequency of the allele bands present and $q$ denotes the frequency of the allele band absent.

\section{RESULTS}

\section{ISSR data analysis}

The genetic diversity among the 21 selected maize genotypes was explored using 20 ISSR markers. Of 25 primers, 20 showed polymorphism. Only the polymorphic primers were included in the final analysis.

A total of 190 different alleles were amplified by the 20 ISSR primers yielding an average of 9.5 ISSR alleles per locus. ISSR primer UBC-810 generated efficient marker profiles for all 21 maize genotypes (Figure 1). Primer UBC-810 showed the highest number of polymorphic alleles (17), followed by primer UBC-815, which scored 14 polymorphic alleles. The lowest number of alleles was found for UBC-809, which showed only four polymorphic alleles (Table 3 ). The PIC ranged from 0.17 to 0.47 . Primer UBC- 810 showed the maximum PIC value, followed by UBC-811. By contrast, UBC-805 showed the lowest PIC value (Table 3).

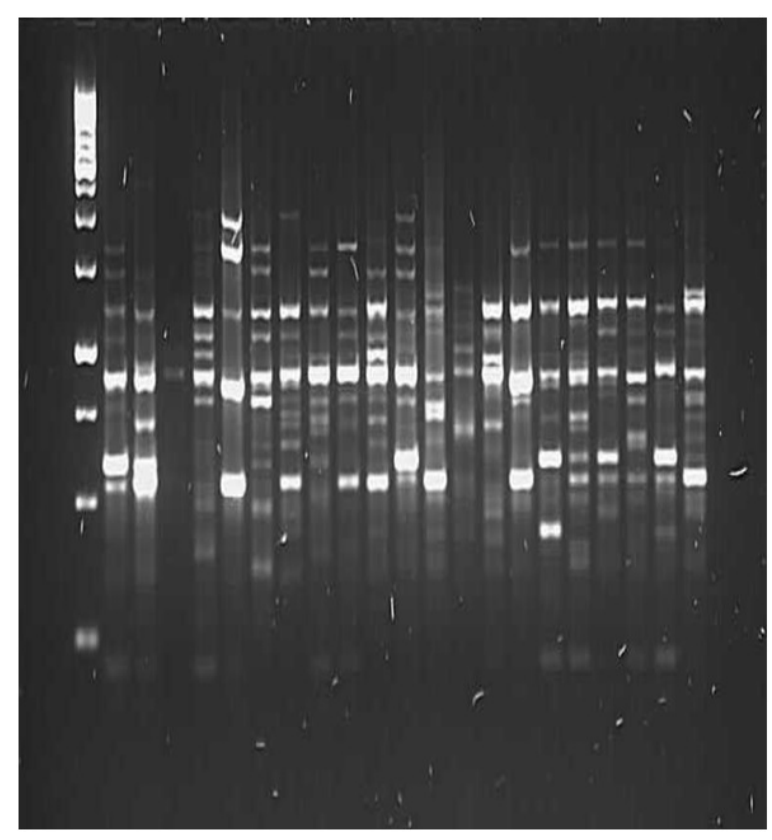

Figure 1. PCR amplification profile of 21 maize genotypes using ISSR primer UBC-810.

Genetics and Molecular Research 16 (1): gmr16019438 
Table 3. List of ISSR markers and their polymorphism information.

\begin{tabular}{l|c|c|c|c}
\hline Primer & Polymorphic bands & Monomorphic bands & Polymorphism (\%) & PIC \\
\hline UBC-801 & 10 & 0 & 100 & 0.32 \\
\hline UBC-802 & 11 & 4 & 73 & 0.41 \\
\hline UBC-803 & 6 & 0 & 100 & 0.42 \\
\hline UBC-804 & 8 & 0 & 85 & 0.37 \\
\hline UBC-805 & 12 & 2 & 100 & 0.17 \\
\hline UBC-806 & 9 & 0 & 100 & 0.24 \\
\hline UBC-807 & 7 & 0 & 100 & 0.33 \\
\hline UBC-808 & 6 & 0 & 94 & 0.32 \\
\hline UBC-809 & 4 & 0 & 100 & 0.22 \\
\hline UBC-810 & 17 & 1 & 100 & 0.47 \\
\hline UBC-811 & 7 & 0 & 80 & 0.46 \\
\hline UBC-813 & 8 & 0 & 88 & 0.40 \\
\hline UBC-814 & 12 & 3 & 73 & 0.40 \\
\hline UBC-815 & 8 & 1 & 100 & 0.31 \\
\hline UBC-816 & 14 & 5 & 100 & 0.45 \\
\hline UBC-817 & 6 & 0 & 72 & 0.41 \\
\hline UBC-818 & 10 & 0 & 92 & 0.19 \\
\hline UBC-819 & 8 & 3 & & 0.42 \\
\hline UBC-820 & 13 & 1 & & 0.32 \\
\hline
\end{tabular}

A genetic similarity matrix for 21 maize accessions was constructed following Randi et al. (1989) (Table 4). The genetic similarity coefficient, based on the polymorphic ISSR markers, ranged from 0.888 to $0.118 \%$. The highest similarity coefficient was found between accessions 12 (015224) and 9 (015114), whereas the lowest similarity was found between genotypes 20 (EV-5098) and 14 (015030) showing genetic variation among 21 maize accessions.

Table 4. Average estimates of genetic similarity using 20 inter simple sequence repeat (ISSR) primers.

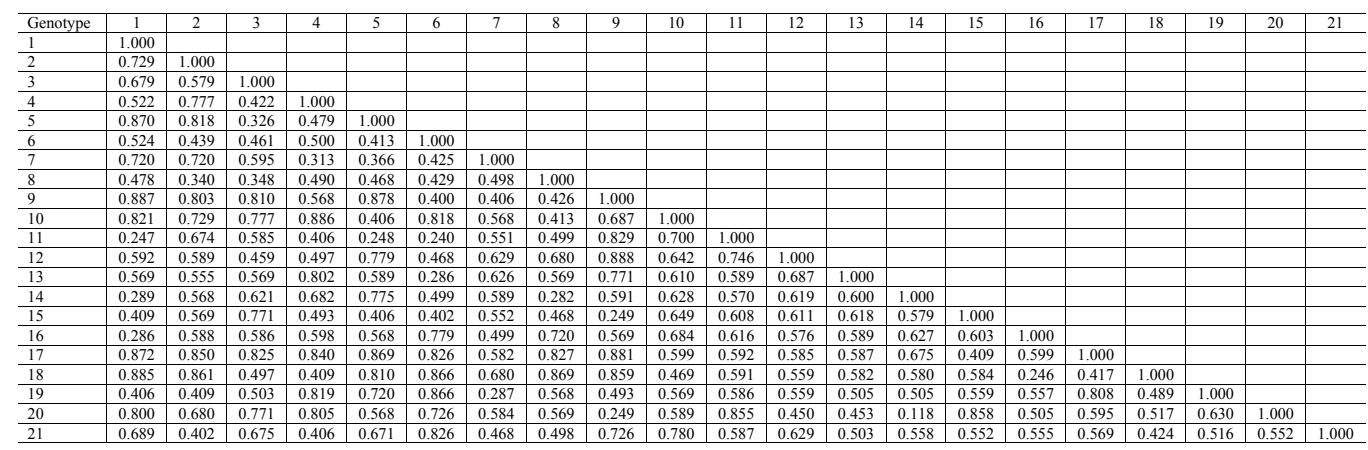

A cluster analysis was done on the basis of similarity values shown in Figure 2. The dendrogram showed two major clusters (Group 1 and Group 2). Group 2 was further subdivided into two groups G1 and G2. G2 could be further subdivided into two subgroups G2A and G2B. The accessions that grouped in subgroups G2A and G2B were more similar to each other compared to genotypes located in other groups. For example, genotypes 4 (014936) and 10 (015182), which were located in subgroup G2A, were more similar or more closely related compared to genotypes from other subgroups. Genotypes 8 (015084) and 16 (015129) showed the maximum dissimilarity with the rest of the genotypes. Finally, 14 genotypes

Genetics and Molecular Research 16 (1): gmr16019438 
(014955, 015084, 015114, 015135, 015224, 015030, 015125, 015129, 015262, Sahiwal-2002, Agaiti-2002, EV-5098, and EV-6098) were selected for use in future breeding programs.

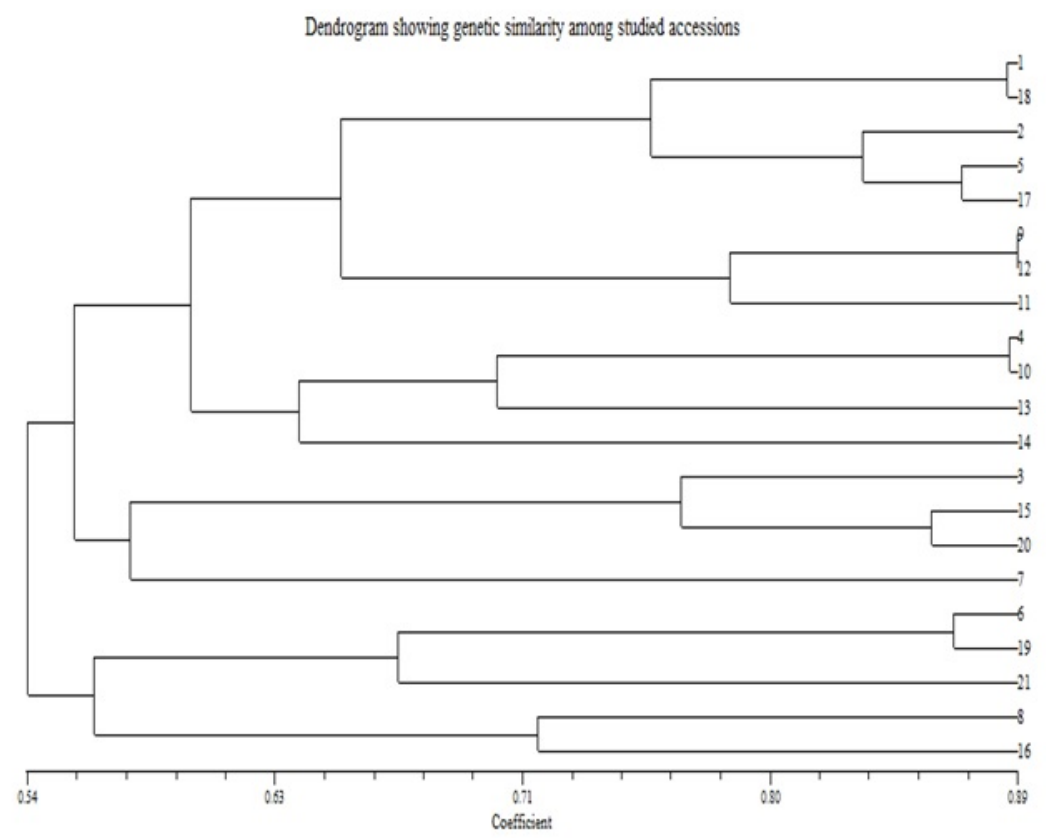

Figure 2. UPGMA dendrogram of 21 maize genotypes based on ISSR marker data. The accessions grouped into two clusters (Group 1 and Group 2).

\section{DISCUSSION}

Genetic diversity is a very important phenomenon for the success of crops in field. If diversity is not observed in the genetic material, it is impossible to obtain the best performance of the plant with other desirable parameters because selection is based on genetic variability. It is necessary to evaluate germplasms using molecular tools like ISSR markers because selection based on phenotypic parameters is suboptimal due to certain limitations such as environmental variations (Hoxha et al., 2004).

The results obtained from the molecular characterization indicated that sufficient genetic diversity was present $(0.88-0.11)$ among the studied genotypes. Therefore, the genetic diversity revealed in this study is a resource that may be used for successful hybrid breeding programs. Júnior et al. (2011) revealed genetic diversity among maize genotypes using 15 ISSR primers and amplified 266 bands, out of which 228 (88.9\%) were polymorphic. Likewise, Najaphy et al. (2012) observed genetic diversity in wheat genotypes using ISSR markers and identified sufficient polymorphisms and reproducible fingerprint profiles. The high polymorphism rates $(88 \%)$ found in UBC-810 and other ISSR primers in this study indicated that molecular characterization of genotypes using ISSR markers is an efficient strategy. This level of polymorphism is similar to results found in previous studies (Agostini et al., 2008; Trindade et al., 2008 Agostini et al., 2010). Júnior et al. (2011) identified a range of polymorphic alleles between 4-11, which was lower than that observed in the present study. This indicates 
that the germplasm accessions studied here have more genetic diversity. Carvalho et al. (2002) also revealed $75.8 \%$ polymorphism using ISSR markers in maize, which is in accordance with the results obtained in the present study. Our study revealed the efficiency of ISSR markers in the identification of variability among maize genotypes. PIC values, as obtained in this study, have been extensively used in various genetic diversity analyses. The moderate to high PIC values obtained here indicate the importance of DNA markers in germplasm analysis, gene mapping, and molecular breeding (Khaled et al., 2015). The PIC values obtained in this study also show the diverse nature of these maize genotypes.

The cluster analysis based on the UPGMA method was used to group genotypes based on similarity. Genotypes located in different clusters should be considered for genetic enhancement programs or hybrid breeding programs. Genotypes located in the same group are more closely related and care should be taken when using similar genotypes in hybrid breeding programs. In this study, we observed 14 genotypes that may be suitable for future genetic enhancement programs based on their diversity. Júnior et al. (2011) also identified different clusters of maize genotypes using ISSR markers. The division of accessions in different groups shows that they are diverse and can be used in future breeding program. Other researchers have also used similar methodologies to select diverse genotypes based on morphological and molecular traits (Munhoz et al., 2009; Silva et al., 2009). Our results suggest that the studied genotypes are diverse and may be utilized for further breeding programs.

\section{Conflicts of interest}

The authors declare no conflict of interest.

\section{ACKNOWLEDGMENTS}

Research supported by the Pakistan Agricultural Research Council, Islamabad, Pakistan. We pay our gratitude to Dr. Nadeem Amjad, Chairman, Pakistan Agricultural Research Council, Islamabad, Pakistan and Dr. Asif Ali, Worthy Voice Chancellor, Mian Nawaz Shareef, University of Agriculture, Multan, Pakistan for encouragement to carry out this study. We are also thankful to the National Agriculture Research Centre, Islamabad, Pakistan for providing the germplasm to initiate the study. We also acknowledge the technical assistance and moral support of all scientists and technical staff at the Genomics lab in the Department of Plant Breeding and Genetics, Faculty of Agricultural Sciences and Technology, Bahauddin Zakaryia University, Multan, Pakistan, enabling the successful completion of the study.

\section{REFERENCES}

Agarwal M, Shrivastava N and Padh H (2008). Advances in molecular marker techniques and their applications in plant sciences. Plant Cell Rep. 27: 617-631. http://dx.doi.org/10.1007/s00299-008-0507-z

Agostini G, Echeverrigaray S and Souza-Chies TT (2008). Genetic relationships among South American species of Cunila D. Royen ex L. based on ISSR. Plant Syst. Evol. 274: 135-141. http://dx.doi.org/10.1007/s00606-008-0037-8

Agostini G, Echeverrigaray S and Souza-Chies TT (2010). Genetic diversity of the endangered Brazilian endemic herb Cunila menthoides Benth. (Lamiaceae) and its implications for conservation. Biochem. Syst. Ecol. 38: 1111-1115. http://dx.doi.org/10.1016/j.bse.2010.12.001

Ahmad MA, Khan SH, Khan AS, Kazi AM, et al. (2014). Identification of QTLs for drought tolerance traits on wheat chromosome 2A using association mapping. Int. J. Agric. Biol. 16: 862-870.

Genetics and Molecular Research 16 (1): gmr16019438 
Ashraf J, Malik W, Iqbal MZ, Ali Khan A, et al. (2016). Comparative Analysis of Genetic Diversity among Bt Cotton Genotypes Using EST-SSR, ISSR and Morphological Markers. J. Agr. Sci. Tech. 18: 517-531.

Bernardo R (2008). Molecular markers and selection for complex traits in plants: learning from the last 20 years. Crop Sci. 48: 1649-1664. http://dx.doi.org/10.2135/cropsci2008.03.0131

Carvalho VP, Ruas PM, Ruas CF, Ferreira JM, et al. (2002). Assessment of genetic diversity in maize (Zea mays L.) landraces using inter simple sequence repeat (ISSR) markers. Crop Breed. Appl. Biotechnol. 2: 557-568. http:// dx.doi.org/10.12702/1984-7033.v02n04a09

Cox TS, Murphy JP and Rodgers DM (1986). Changes in genetic diversity in the red winter wheat regions of the United States. Proc. Natl. Acad. Sci. USA 83: 5583-5586. http://dx.doi.org/10.1073/pnas.83.15.5583

Dalamu Behera TK, Gaikwad AB, Saxena S, Bharadwaj C et al. (2012). Morphological and molecular analyses define the genetic diversity of Asian bitter gourd (Momordica charantia L.). Aus. J. Crop Sci. 6: 261-267.

Ghislain M, Zhang D, Fajardo D, Hanuman Z, et al. (1999). Marker-assisted sampling of the cultivated Andean potato Solanum phureja collection using RAPD markers. Genet. Resour. Crop Evol. 46: 547-555. http://dx.doi. org/10.1023/A:1008724007888

Edwards K, Johnstone C and Thompson C (1991). A simple and rapid method for the preparation of plant genomic DNA for PCR analysis. Nucleic Acids Res. 19: 1349. http://dx.doi.org/10.1093/nar/19.6.1349

Helentjaris T, Slocum M, Wright S, Schaefer A, et al. (1986). Construction of genetic linkage maps in maize and tomato using restriction fragment length polymorphisms. Theor. Appl. Genet. 72: 761-769. http://dx.doi.org/10.1007/ BF00266542

Hoxha S, Shariflou MR and Sharp P (2004). Evaluation of genetic diversity in Albanian maize using SSR markers. Maydica 49: 97-103.

Islam AKMR and Shepherd KW (1992). Production of wheat-barley recombinant chromosomes through induced homoeologous pairing : 1. Isolation of recombinants involving barley arms 3HL and 6HL. Theor. Appl. Genet. 83: 489-494. http://dx.doi.org/10.1007/BF00226538

Júnior ATA, Oliveira EC, Gonçalves LSA, Scapim CA, et al. (2011). Assessment of genetic diversity among maize accessions using inter simple sequence repeats (ISSR) markers. Afr. J. Biotechnol. 10: 15462-15469. http://dx.doi. org/10.5897/AJB10.2624

Khaled AGA, Motawea MH and Said AA (2015). Identification of ISSR and RAPD markers linked to yield traits in bread wheat under normal and drought conditions. J. Genet. Eng. Biotechnol. 13: 243-252. http://dx.doi.org/10.1016/j. jgeb.2015.05.001

Marić S, Bede M, Martinčić J and Guberac V (1998). Variability of some winter wheat traits from breeding process. Sjemenarstvo 15: 421-433.

Munhoz RE, Prioli AJ, Amaral AT, Jr., Scapim CA, et al. (2009). Genetic distances between popcorn populations based on molecular markers and correlations with heterosis estimates made by diallel analysis of hybrids. Genet. Mol. Res. 8: 951-962. http://dx.doi.org/10.4238/vol8-3gmr592

Najaphy A, Parchin RA and Farshadfar E (2012). Comparison of phenotypic and molecular characterizations of some important wheat cultivars and advanced breeding lines. Aust. J. Crop Sci. 6: 326-332.

Randi E, Spina F and Massa B (1989). Genetic variability in Cory's shearwater (Calonectris diomedea). Auk 106: 411-417.

Reddy MP, Sarla N and Siddiq EA (2002). Inter simple sequence repeat (ISSR) polymorphism and its application in plant breeding. Euphytica 128: 9-17.

Sajjad M, Khan SH and Khan AS (2011). Exploitation of germplasm for grain yield improvement in spring wheat (Triticum aestivum). Int. J. Agric. Biol. 13: 695-700.

Schlötterer C (2004). The evolution of molecular markers--just a matter of fashion? Nat. Rev. Genet. 5: 63-69. http:// dx.doi.org/10.1038/nrg1249

Schulman AH (2007). Molecular markers to assess genetic diversity. Euphytica 158: 313-321. http://dx.doi.org/10.1007/ s10681-006-9282-5

Silva TA, Pinto RJB, Scapim CA, Mangolin CA, et al. (2009). Genetic divergence in popcorn genotypes using microsatellites in bulk genomic DNA. Crop Breed. Appl. Genet. 9: 31-36. http://dx.doi.org/10.12702/1984-7033.v09n01a05

Tautz D (1989). Hypervariability of simple sequences as a general source for polymorphic DNA markers. Nucleic Acids Res. 17: 6463-6471. http://dx.doi.org/10.1093/nar/17.16.6463

Trindade H, Costa MM, Lima SB, Pedro LG, et al. (2008). Genetic diversity and chemical polymorphism of Thymus caespititius from Pico, São Jorge and Terceira islands (Azores). Biochem. Syst. Ecol. 36: 790-797. http://dx.doi. org/10.1016/j.bse.2008.09.001

Welsh J and McClelland M (1990). Fingerprinting genomes using PCR with arbitrary primers. Nucleic Acids Res. 18: 7213-7218. http://dx.doi.org/10.1093/nar/18.24.7213

Genetics and Molecular Research 16 (1): gmr16019438 